\title{
Performance assessment of health care providers
}

\author{
Rasha Abd Elhameed Ali* Seham Ahmed Fouad** \\ *Assistant Professor **Assistant lecturer
}

Performance appraisal is one of the important components in the rational and systematic process of human resource management. The information obtained through performance appraisal provides foundations for recruiting and selecting new hires, training and development of existing staff, and motivating and maintaining a quality work force by adequately and properly rewarding their performance. A reliable performance appraisal system, would protect a human resource management system from falling apart, decreasing the total waste of the valuable human assets a company has. it should be viewed as only one of a number of mechanisms for improving the quality of clinical care (Armstrong \& Baron, 1998).

Performance appraisal had been defined by DeVries and colleges in 1981 as the process which allows firms to measure and consequently evaluate an employee's achievements and behavior over a certain period of time (Devries et al.,1981). According to Briscoe and Schuler in 2004 performance can be viewed as a combination of several variables, such as motivation, ability, working conditions and expectations (Brisco \&Schuler, 2004). It has been established that there are certain factors that affect employee's performance more than others. These factors, according to Dowling and colleagues , 1999 included the compensation package; the nature of task; support from higher management; the working environment and the overall corporate culture (Dowling et al., 1999).

Chandra and Frank, in 2004 wrote that "performance appraisal systems are designed to objectively evaluate an employee's performance and then outline measures to be taken for improvements, which are essential for an organization to move ahead. The evaluative purpose is intended to inform people of their performance standing. The developmental purpose is intended to identify problems in employees performing the assigned task. These systems are often organization specific and health care organizations are no exception." (Chandra \& Frank, 2004).

\section{- Purpose of performance appraisal and benefits:}

The primary reason for having a performance appraisal program is to monitor employee's performance, motivate staff and improve hospital morale. In the hospital, monitoring employee performance requires routine documentation, which is accomplished through completing a performance appraisal form (Berwick, 1989).

When employees are aware that the hospital is mindful of their performance and they could be rewarded with increment and promotions, they will work harder. Morale is improved when employees receive recognition or reward for their work. An effective performance appraisal program will assist the hospital in achieving its goals and objectives (Berwick, 1989). Not only, training needs will be identified and addressed during a performance appraisal review, but also hidden talent can be discovered as well. Through identifying these training needs, staff can perform their jobs at the highest level and be in a better position to address clients, members and customers concerns and questions (Berwick, 1989).

A well-developed staff is more likely to be proactive, productive and resourceful, all of which helps give the hospital a competitive edge, from improved customer relations to increased profits. In hospital, thus the 
SOHAG MEDICAL JOURNAL Vol. 22 No.3 October 2018

primary objective of performance appraisal is to improve the quality of healthcare practice (Berwick, 1989). This is the anticipated result of informing physicians of possible performance deficiencies, as in the model of the quality improvement cycle and the educational model of practice reflection. If serious performance deficiencies were identified during review by the Physician Performance Committee, under its existing authority, direct detailed evaluation, may be required

The Department of Health London in 1999 had been emphasized this point by stating that it is not the primary aim of appraisal to scrutinize doctors to see if they are performing poorly but rather to help them consolidate and improve on good performance aiming towards excellence. In addition, the employers reported that the appraisals were intended to help improve performance through the identification of training and development needs and to assist with the assessment of future potential and decisions on career progression (Hogg, 1988).

In the health sector, resource availability and employee competence are essential but are not enough to guarantee desired employee performance (Franco et al., 2002). To obtain performance on quality, cost and patient satisfaction dimensions, health organizations will also have to satisfy their physicians and employees (Griffith, 2000). Health care delivery is high labor-intensive (Franco et al., 2002) and health sector performance is critically dependent on employee motivation (Amaratunga \& Baldry, 2002, Franco et al., 2002, and Martinez \& Martineau, 1998). The ultimate aim of performance management (or performance appraisal), in hospital, is to optimize assessment of health care providers Seham Ahmed Fouad

the quality of work and efficiency in the health system. Quality may simply be defined as fitness for purpose (Acute Care Hospitals, 1991). All approaches to quality assurance share the common theme of measuring actual performance and its comparison with either expected or normative standards. Hospitals are aware that well developed appraisal systems increase the probability of retaining, motivating and promoting productive people. The proper management of human resources is a critical variable affecting an employee's productivity. So performance appraisals are seen as an essential tool for the effective management of organizational human resource (Latham \& Wexley, 1994).

\section{- Who will appraise performance?}

Physicians, nurses, social workers, clinical pharmacists and other professionals often work interdependently to care for patients; but during performance appraisal, they have formal input into each other's appraisals. As hospitals increasingly focus on care delivery processes, physicians may be appraised by other professionals who share the responsibility for patient care and outcomes. Ensuring the quality of medical care is the responsibility of both regulatory bodies and hospitals. The way an organization is structured has a direct bearing on who conducts the appraisal. Hospitals generally use a combination of functional and, team or program approaches.

- In a functional approach, professionals focus on performing their own functions under the direct supervision of one boss.

- Teams or programs comprise individual professionals who also belong to traditional functional departments. In this case, however, professionals may have two 
SOHAG MEDICAL JOURNAL Vol. 22 No.3 October 2018

supervisors - one in the department and one in the team or program.

The peer review program of the College of Physicians and Surgeons of Ontario showed that the office records of randomly selected physicians tended to improve after defects were pointed out (Norton et al., 1998). A British study by Hearnshaw and colleagues in 1996 had suggested that the routine practice of doctors and nurses can be influenced by feedback from patients (Hearnshaw et al., 1996). Another study in same aspect reported the feasibility and value of physician performance appraisal by patients (Lewis \& Williamson, 1995), peers (Ramsey et al., 1993), and hospital nurses (Wenrich et al., 1993).

Ramsey and colleagues in 1996 had reported that the method of selecting peer or patient raters (by the physician, by the investigators, or at random from lists of associates or patients) does not influence ratings (Ramsey et al., 1996). Physician must ensure that standards established by the team are met; both the nursing manager and physician would provide feedback to the nurse in question. Responsibilities of the department head, also called the chief of service. Generally, the department head is responsible for assessing the clinical expertise and ensuring compliance with expectations; however, many hospitals have not yet fully implemented such a system.

- What performance will be appraised?

The nature of the performance to be evaluated is ambiguous. In many cases the appraisal considers the practitioner's decisions about when individual practice patterns take precedence over practice guidelines. The jury is out on how to develop expectations for practice, but to assess the quality of a department's service such expectations must be developed.

\section{Seham Ahmed Fouad}

Health Services Research Group in 1992 wrote an article in (CMAJ) Canadian Medical Association Journal and reviewed the challenge of developing standards, guidelines and clinical policies as well as defining "quality" in relation to performance. Performance measures often include both process expectations (how the work gets done) and outcome expectations (the results of the process).

Acute Care Hospitals in 1991 decided that in addition to evaluating clinical performance of the hospital employee, appraisers also take into account that employee are expected to work effectively with other staff; respect bylaws, regulations, policies and procedures; and participate in committees, staff development activities and continuing education (Acute care hospital, 1991). Simon L. in 1992 suggested the following criteria to assess the performance of department head in the hospital: quality of service in the specific department, operational efficiency and effectiveness, and budget responsibility and accountability (Simon, 1992).

The College of Physicians and Surgeons of Alberta in 1995 established the Physician Performance Advisory Committee to establish a process to evaluate physician performance. Extensive discussions within the committee generated six broad categories of physician performance attributes - medical knowledge and skills, attitudes and behavior, professional responsibilities, practice improvement activities, administrative skills and personal health. Moorhead and Griffin in 1992 described that the process will evaluate work behaviors by measurement and comparison to previously established standards, recording the results, and 
SOHAG MEDICAL JOURNAL Vol. 22 No.3 October 2018

communicating them back to the employee. It is an activity between a manager and an employee. General Medical Council, London \& Royal College of Physicians and Surgeons of Canada wrote the seven key roles, which are being expected from specialist physician in the hospital as a permanent employee, in their reports. So any physician can be evaluated on the basis of these roles.

- How performance is appraised? McAuley R.G and colleagues in 1990 conducted a peer assessment program in the College of Physicians and Surgeons of Ontario that is mainly covering the office practices (Auley, 1990). Kilshaw in 1992 said that these programs are traditionally based on peer review and include a well-defined committee structure involving medical staff representatives (Kilshaw, 1992). The College of Physicians and Surgeons of Alberta 1995 in one report established five categories of sources of physician assessment - self, patients, medical peers or colleagues, consulting physicians to whom patients are referred and non-physician coworkers in health care (e.g., secretaries, nurses and pharmacists). Lemieux-Charles in 1989 described that in hospitals, department heads, various medical committees and ultimately the board of directors are responsible for ensuring standards of medical care. Although hospitals are beginning to formalize the evaluation process; many department heads are reluctant to appraise their colleagues' performance (Lemieux-Charles, 1989). Department head positions are often time-limited; as a result, the incumbents often find it difficult to judge colleagues when they know they will be working with them again interdependently at the end of the term. Some hospitals now expect department heads to carry out extensive

\section{Seham Ahmed Fouad}

assessments of each doctor's \& Nurses' performance before recommending reappointment (Lemieux-Charles, 1989).

It is essential that doctors clarify the roles of the medical quality assurance committee and of the department head in assessing performance. Peer appraisal is the system that is most familiar and acceptable to hospital employee. They are most likely to evaluate a colleague's performance through a formal peer evaluation system or to establish goals for their own performance through feedback sessions with the department head. The appraisal is usually conducted in a oneto-one interview. It is recommended that all appraisers are specifically trained for this task (Lemieux-Charles, 1989).

It is important that appraise becomes clear about exactly what to expect from the appraisal, so that any negative feelings and insecurities can (at least in part) be reduced (Jackson et al, 2001 and Wilkinson, 2001). Although there are peer-review instruments that validated by Ramsey and colleges in 1993, which could be used to assess ,working relationships with colleagues $^{\text {ee }}$ they are yet to be implemented widely.

-Approaches for assessing the performance:

The specification of performance appraisal criteria is a recurring problem (Leatt \& Fried, 1988). One of the central issues is whether to evaluate traits, behaviors or outcomes of work.

1- The trait approach, which is now outdated, evaluated such items as appearance, self-confidence, alertness and ambition rather than job-related behaviors, productivity or quality of work.

2- Behavioral approaches identify critical job-related activities and behaviors and appraise the person's 
SOHAG MEDICAL JOURNAL Vol. 22 No.3 October 2018
Performance assessment of health care providers Seham Ahmed Fouad performance of these activities. (Behaviorally anchored rating scales (BARS), which describe different levels of performance along a scale, exemplify the current application of this approach). For example, a scale that measures the behaviors associated with assessing a patient with chest pain would include a list of behavioral descriptions, from the worst level of performance to the best, with appropriate levels in between. Such an approach is a large task and approximates some of the steps taken in developing clinical practice guidelines. The behavioral approach can be used in conjunction with peer evaluation. Three types of peer evaluation have been described: peer rating, peer ranking and peer nomination (Stone \& Melt, 1993).

1. In peer rating, group members rate each other.

2. In peer ranking, group members assign rankings to one another.

3. In peer nomination, each member of a well-defined group designates a number of group members as highest (and sometimes lowest) in an aspect of performance.

The third type has been shown to distinguish with a high degree of reliability and validity group members whose performance is very good or very poor in the particular area (Kane \& Lawler, 1978). When there are few peers in the organization and the practice to be assessed is complex, a peer in the specialty from outside the organization conducts the evaluation.

3- Outcome approaches such as management by objectives and goal setting focus on the results of performance rather than on behaviors. Results-oriented systems are as much approaches to management as they are appraisal systems; the focus is on setting targets ahead of time so that employees know where to aim. Such approaches are based on the idea that people are more motivated and that their performance is improved when they have specific goals. There are three reasons why setting goals affects performance: it has a directive effect (channeling energy on a particular path), it requires workers to put forth effort and it requires them to be persistent - to expend directed effort over time (Latham, 1990). Generally, goals and ways of measuring their achievement are mutually established by the supervisor and the subordinate or among peers. In this way issues that are difficult to quantify but relevant to professional work can be addressed. There is a continuing debate over the merits of behavioral versus outcomeoriented performance criteria (Latham, 1990).

\section{- When performance is appraised?}

In most cases physicians' performance is appraised annually when their credentials are renewed. Special cases may be addressed throughout the year. The more timely the feedback, the more likely it will influence performance. Communication must be continual to have an effect on attitudes. Therefore, the frequency of the appraisal depends on its function, the nature of the work and the characteristics of the person whose work is appraised.

- How feedback is given?

Ideally, the timing of feedback should be flexible, depending on the needs of the professional and the organization. As Von Glinow noted in 1989, physicians were generally reluctant to address difficult performance situations formally. Poor methods of giving feedback can increase tensions in relationships that may already be strained. What factors will predispose a professional to listen to the issues presented? First, feedback must be 
SOHAG MEDICAL JOURNAL Vol. 22 No.3 October 2018
Performance assessment of health care providers Seham Ahmed Fouad

seen as coming from a credible source

closely with the person being appraised

- the appraiser must possess the necessary expertise, be trustworthy and work interdependently and possibly
(Von Glinow, 1989). Feedback is likely to be disregarded if the credibility issue is not addressed.

\section{*Guidelines for providing feedback during performance appraisals.}

1. Focus on relevant performance, Behavior or outcomes, not on the individual as a person.

2. Present perceptions, reactions and opinions as such and not as facts.

3. Focus on specific, observable behavior, not on general, global impressions.

4. For feedback that is evaluative rather than descriptive, focused on established criteria.

5. Avoid loaded terms that produce an emotional reaction or raise defenses.

6. Focus on the area over which the person can exercise some control or for which he or she can use the feedback to improve or to plan alternative actions.

7. When encountering with defensive reactions, deal with the reactions rather than trying to convince, reason or supply other information.

8. Use a method of communication that conveys acceptance of the person as worthwhile with the right to be different.

*Adopted from center for creative leadership, 1976

Feedback sessions are generally conducted one-on-one. However, a peer review survey suggested that feedback on quality-of-care issues conducted by a group of physicians can improve individual physician practice (Gombeski et al., 1992).

- Methods used for performance appraisal:

Methods can be either direct or indirect evaluations of performance. Direct methods concern observations of actual doctor-patient encounters and indirect methods retrospectively reflect the result of a doctor-patient interaction. Simulated patients, video observation and direct observation are direct methods, whereas peer assessment, portfolios or appraisals and audit of medical records are examples of indirect evaluations.

1- Simulated patients: Five studies investigated the use of covert SPs in routine practice. An incognito SP visits a doctor and rates his or her performance using pre-defined criteria. Ratings by SPs in 1 study were checked with an expert panel, which rated the tape-recorded consultations

(Beaulieu et al., 2003)

2- Video observation: Nine studies carried out in the Netherlands and the UK explored video observation in the routine practice of GPs. Doctor consultations were videotaped and scored by 1 or 2 observers.

3- Peer assessment: In 23 studies peer ratings were used to provide an indicator of a doctor's performance. Medical colleagues or co-workers completed confidential questionnaires regarding knowledge, communication skills, professionalism, management and collegiality. Sometimes, patient ratings were added. Other terms used instead of 'peer assessment' are '360degree feedback' and 'multi-source feedback'.

4- Portfolio or appraisal: Portfolio or appraisal were investigated in 11 studies. Appraisal refers to a structured process of facilitated self-reflection (Bruce Det al., 2004). A portfolio or appraisal folder may be described as a collection of evidence maintained and presented for a specific purpose (Mathers et al., 1999). A mentoring system is a key element for portfolios and appraisals. The UK introduced appraisals in April 2005 in general 
SOHAG MEDICAL JOURNAL Vol. 22 No.3 October 2018

practice. Portfolio is being studied for pediatric registrars and GPs in the UK (Mathers et al., 1999).

5- Direct observation: In 3 studies doctors were observed and assessed directly during consultations, ward rounds or in the operating theatre. In all studies, an instrument was used to rate performance on, for example, history taking, physical examination and/or communication skills (Norgaard et al., 2004 and Filho \& Schonhorst, 2004).

6- Audit of medical records: Audit of medical records or referral letters can be used to measure doctor performance, as reported in 10 studies. For instance, Norton et al. developed the Peer Assessment Program in Canada in 1984 to assess medical records (Norton et al., 1998). Doctors being assessed in this program in Canada were randomly chosen from the College's register, were above the age of 70 years or were directly referred by a complaint committee.

\section{References:}

- Acute Care Hospitals (1991), Canadian Council on Health Facilities Accreditation, Ottawa, p.-465.

- Amaratunga, D. \& D. Baldry (2002), "Performance measurement in facilities management and its relationship with management theory and motivation", Facilities, Vol. 20, N.10, pp. 327-336.

- Armstrong, M. \& Baron, A. (1998), "Out of the tick box", People Management, Vol 15, N.4, pp. 38-41.

- Beaulieu MD, Rivard M, Hudon E, Saucier D, Remondin M, Favreau $R$ (2003). Using standardised patients to measure professional performance of physicians. Int $\mathrm{J}$ Qual Health Care; $15: 251-9$.

- Berwick, DM (1989), "Continuous improvement as an ideal in health care", N Engl J Med, 320:53-6.

- Briscoe, D. \& Schuler, R. (2004), "International Human Resource Management" 2nd Ed., Routledge. assessment of health care providers

Seham Ahmed Fouad

- Bruce D, Phillips K, Reid R, Snadden D, Harden R (2004). Revalidation for general practitioners: randomised comparison of two revalidation models. BMJ;328:687-91.

- Chandra, A. \& Frank, ZD (2004), "Utilization of performance appraisal systems in health care organizations and improvement strategies for supervisors", Health Care Manag (Fredrick), Jan -Mar 23(1):25-30.

- DeVries, D.L., Morrison, A.M., Shullman, S.L., \& Gerlach, M.L. (1981), "Performance Appraisal On The Line", Center for Creative Leadership, Vol.23, N.-4, p.50.

- Dowling et al (1999), "International Human Resource Management Managing People in a Multinational Context”, 3rd Ed., International Thomson Publishing.

- Filho GRD, Schonhorst L (2004). The development and application of an instrument for assessing resident competence during pre-anaesthesia consultation. Anesth Analg;99:62-9.

- Franco, L. M., S. Bennett \& R. Kanfer (2002), "Health sector reform and public sector health worker motivation: a conceptual framework", Social Sciences \& Medicine, Vol. 54, pp. 1255-1266.

- Gombeski, WR, Day, JR \& Fay, GW et al (1992), "Physician peer review surveys: Management tool for improving quality of patient care", $J$ Health Care (Mark), 12 (2): 52-59.

- Griffith, J. R. (2000), "Championship Management for Healthcare Organizations", Journal of Healthcare Management, Vol. 45, N. 1, January/February, pp. 17-31.

- Hogg, C. (1988), "Performance appraisal (Fact Sheet 3)", London: Personnel Publications. Hospital University Kebangsaan Malaysia.Jurnal Kesihatan Masyarakat, 12 (1). pp. 9-18.

- Jackson, P., Gale, C., Bishop, I., et al (2001), "Appraisal -three case studies", Clinician in Management, 10, 38-44.

- Kane, J.S., Lawler, E.E. III (1978), "Methods of peer assessment", Psychol Bull, 85: 555-586. 
SOHAG MEDICAL JOURNAL Vol. 22 No.3 October 2018
Performance assessment of health care providers Seham Ahmed Fouad
- Kilshaw, M.F. (1992), "Implementing an effective quality assurance program", In Gellman D (ed):The CMA Guide to Medical Administration in Canadian Hospitals, CMA, Ottawa, pp 1-15.

- Latham, G. (1990), "The role of goal setting in human resource management", In Ferris GR, Rowland KM (eds): Performance Evaluation, Goal Setting and Feedback, Jai Pr, Greenwich, Conn,185-216.

- Latham, G.P. \& Wexley, K.N. (1994), "Increasing productivity through performance appraisal", 2nd ed., Addison-Wesley, New York.

- Leatt, P. \& Fried, B. (1988), "Technology and human resources management", In Fottler MD, Hernandez SR, Joiner CL (eds): Strategic Management of Human Resources in Health Services Organizations, Delmar, Albany, NY, 85-111.

- Lemieux-Charles, L. (1989), "Hospital-Physician Integration: the Influence of Individual and Organization Variables on Integration (doctoral thesis)", University of Toronto, Toronto.

- Lewis, J.R. \& Williamson, V. (1995), "Examining patient perceptions of quality care in general practice: comparison of quantitative and qualitative methods", $\mathrm{Br} J$ Gen Pract, 45:249-53.

- Martinez, J. and Martineau, T. (1998), "Rethinking human resource: An agenda for the millennium", Health Policy and Planning, Vol. 13, N. 4, pp. 345-358.

- Mathers NJ, Challis MC, Howe AC, Field NJ (1999). Portfolios in continuing medical education effective and efficient? Med Educ ;33:521-30.

- McAuley RG, Paul WM, Morrison GH et al (1990), "Five-year results of the peer assessment program of the College of Physicians and Surgeons of Ontario", Can Med Assoc J, 143: 11931199.
- Norgaard K, Ringsted C, Dolmans D (2004). Validation of a checklist to assess ward round performance in internal medicine. Med Educ ;38:7007

- Norton, P.G., Dunn, E.V., Beckett, R. \& Faulkner, D. (1998), "Long term follow-up in the Peer Assessment Program for non-specialist physicians in Ontario, Canada", Jt Comm J Qual Improv, 24:334-41.

- Norton, P.G., Dunn, E.V., Beckett, R. \& Faulkner, D. (1998), "Long term follow-up in the Peer Assessment Program for non-specialist physicians in Ontario, Canada", Jt Comm J Qual Improv, 24:334-41.

- Ramsey, P. G., Wenrich, M. D., Carline, J. D., et al (1993), "Use of peer review ratings to evaluate physician performance", JAMA, 269, 1655-1660.

- Ramsey, P.G., Carline, J.D., Blank, L.L. \& Wenrich, M.D. (1996), "Feasibility of hospital-based use of peer ratings to evaluate the performances of practicing physicians", Acad Med,71:364-70.

- Simon, L. (1992), "Evaluation of department heads", The CMA Guide to Medical Administration in Canadian Hospitals, CMA, Ottawa,F3.2-F3.10.

- Von Glinow, M.A. (1989), "Appraising the performance of professional employees", In Mohrman AM Jr, Resnick-West SM, Lawler EE III: Designing Performance Appraisal Systems: Aligning Appraisals and Organizational Realities, Jossey-Bass, San Francisco, p. - 196.

- Wenrich, M.D., Carline, J.D., Giles, L.M., \& Ramsey, P.G. (1993), "Ratings of the performances of practicing internists by hospital-based registered nurses", Acad Med, 68:6807.

- Wilkinson, S. (2001), "Consultant appraisal scheme: barriers and success factors", Clinician in Management, Vol. 10, pp.-12-14. 
SOHAG MEDICAL JOURNAL Performance assessment of health care providers

Vol. 22 No.3 October 2018 Seham Ahmed Fouad 